\section{Feminicídios em Porto Alegre, Rio Grande do Sul, Brasil: iniquidades de gênero ao morrer}

\author{
Femicide in Porto Alegre, Rio Grande do Sul \\ State, Brazil: gender iniquities in dying
}

\section{Feminicidios en Porto Alegre, Río Grande do Sul, Brasil: inequidades de género al morir}

\section{Resumo}

Feminicídios são assassinatos de mulheres decorrentes das desigualdades de gênero e representam a forma mais extrema da violência contra a mulher. $O$ referencial teórico-metodológico utilizado neste estudo foi a teoria do patriarcado e a análise crítica do discurso. Foram analisados os discursos referentes ao relatório final de 64 inquéritos policiais categorizados como feminicídios, ocorridos na cidade de Porto Alegre, Rio Grande do Sul, Brasil, no período de 2006 a 2010. As vitimas eram majoritariamente mulheres pobres, jovens e moradoras de regiões de periferia, havendo uma frequência elevada de prostitutas e mulheres executadas pelo tráfico; mortes não consideradas feminicídios pelos operadores policiais. Muitos inquéritos foram arquivados devido à ausência de provas e outros não foram nem ao menos iniciados. Nos inquéritos, havia discursos que desqualificavam e culpavam as vitimas, embora alguns criticassem as desigualdades entre homens e mulheres e identificassem os efeitos letais do machismo. Inquéritos policiais são fontes importantes para estudar o feminicídio na sociedade, agregando grande quantidade de informações sobre vítimas, agressores e cenários dos crimes.

Homicídio; Violência contra a Mulher; Sexismo
Stela Nazareth Meneghel 1

Ane Freitas Margarites 2

doi: 10.1590/0102-311X00168516

\author{
Correspondência \\ S. N. Meneghel \\ Escola de Enfermagem, Universidade Federal do Rio Grande \\ do Sul. \\ Rua São Manoel 963, Porto Alegre, RS 90620-110, Brasil. \\ stelameneghel@gmail.com \\ 1 Escola de Enfermagem, Universidade Federal do Rio Grande \\ do Sul, Porto Alegre, Brasil. \\ 2 Hospital de Clinicas de Porto Alegre, Porto Alegre, Brasil.
}




\section{Introdução}

Feminicídios constituem a forma mais extrema de violência baseada em gênero, entendida como aquela exercida pelos homens contra as mulheres, pelo desejo de obter poder, dominação ou controle e representando o final de um continuum de violência 1 .

Estatisticamente há menos assassinatos de mulheres do que de homens, porém, enquanto os homens são mortos por outros homens em ambientes públicos, as mulheres, em sua maioria, são assassinadas em contextos domésticos por homens com os quais mantinham relações de intimidade 2,3. Grande parte dos crimes de gênero perpetrados contra mulheres, especialmente os feminicídios íntimos, ocorre após uma longa rota de violências e constituem mortes anunciadas 4 .

Os feminicídios possuem um significado simbólico, em que a violência é usada para demonstrar poder frente aos outros homens. Esses crimes representam as hierarquias existentes entre mulheres e homens, mantida pela inter-relação de três sistemas de dominação/exploração: o patriarcado 5, o racismo e o capitalismo 6.

A tipificação dos feminicídios em lei inclui a concepção da desigualdade de gênero presente na sociedade como determinante, politizando, portanto, essse tipo de crime. Mesmo assim, ainda se reduzem os motivos dos feminicídios a conflitos nas relações de conjugalidade, a patologias dos agressores e a questões de honra 7 .

O debate acerca do uso do termo femicídio ou feminicídio ainda é relativamente recente por se tratar de um conceito utilizado pela primeira vez por Diana Russel, em 1990 1, frente a um Tribunal Internacional de Direitos Humanos. Marcela Lagarde 8 propôs o uso do termo femicídio para designar quaisquer assassinatos de mulheres e feminicídio para indicar os assassinatos de mulheres por conta do gênero, nos quais há negligência do Estado, o que permite considerá-los crimes de lesa-humanidade. Embora, em pesquisas e trabalhos anteriores, tenha-se optado pela denominação femicídio 9,10,11, a partir da escolha legal brasileira pelo conceito feminicídio na criação da recente lei 12, passouse a usar a terminologia adotada no Brasil.

Um dos problemas que pode haver no acompanhamento dos feminicídios é a invisibilização de parcela de tais assassinatos, tornando fundamental o uso de um conceito amplo e a inclusão de diferentes cenários em que eles acontecem, permitindo abarcar a totalidade desse agravo. Mesmo operadores que atuam nas redes de enfrentamento às violências, geralmente consideram como feminicídios apenas os crimes perpetrados por parceiros íntimos, fato que subestima a prevalência, dificulta a investigação das mortes e a punição dos culpados.

Carcedo 13, ao analisar os feminicídios na América Central, identificou uma série de cenários em que se dão estas mortes, alguns conhecidos de longa data, outros emergentes na atualidade, ampliando os tipos a serem classificados como esse tipo de crime. Os cenários históricos dos crimes contra a mulher compreendem os que ocorrem entre parceiros íntimos em ambiente familiar e doméstico e os assassinatos que seguem a violação sexual, em que as mulheres estão na posição de objetos descartáveis eliminados após a agressão sexual 13,14. Na etapa atual do capitalismo, aumentou a exploração sexual comercial de mulheres; em tal tipo de comércio, a vida pouco vale e os feminicídios entre prostitutas são extremamente elevados 13,15 .

Um último cenário ainda pouco percebido como de risco para o feminicídio é representado pelo tráfico de drogas, armas e migração clandestina. Nesse contexto, as mulheres são convertidas em território de vingança e executadas em lugar dos companheiros pela maior facilidade de serem localizadas.

Pretende-se com este estudo visibilizar um agravo ainda pouco problematizado no campo da saúde coletiva, mas de gravidade e magnitude ascendente. O entendimento da percepção social dessas mortes, por meio dos discursos policiais, auxilia a organizar intervenções efetivas pelas redes de enfrentamento às violências, incluindo o setor saúde. Além disso, em locais onde o Estado está pouco presente e os crimes e as infrações de direitos não são punidos, aumentam as violências. Para isso, é crucial compreender como são construídos socialmente os processos de investigação dessas mortes e ouvir a voz de atores sociais envolvidos no processo. O objetivo deste artigo é analisar os discursos presentes nos relatórios finais de inquéritos policiais de homicídios de mulheres e identificar como essas mortes são percebidas. 


\section{Percurso metodológico}

Este estudo, de recorte qualitativo, inspira-se na Análise Crítica do Discurso (ACD) 16 para analisar os discursos formulados nos inquéritos policiais de mulheres mortas por agressão, na cidade de Porto Alegre, Rio Grande do Sul, Brasil. Faz parte do componente qualitativo da pesquisa denominada Femicídios e Crimes Pautados em Gênero no Rio Grande do Sul 17, e as informações são oriundas de inquéritos policiais, referentes a assassinatos de mulheres, ocorridos no período de 2006 a 2010, com investigação concluída até 2013 e categorizados como feminicídios pelo grupo de pesquisa. Consideraram-se como discursos os textos escritos e documentados nos inquéritos policiais, não fazendo parte da análise as conversas ocorridas na Delegacia de Homicídios da Polícia Civil.

A ACD formulada por Fairclough 16 pauta-se em três dimensões: a produção textual, que inclui o vocabulário, a gramática e a estrutura textual; as práticas discursivas, referentes à produção, distribuição e consumo de textos na sociedade ou como esses discursos são interpretados socialmente e, finalmente, a prática social, que, para o autor, ancora-se nas noções de ideologia e poder. No processo de análise dos inquéritos policiais, utilizaram-se algumas técnicas e ferramentas da ACD, contudo não foi feito um estudo linguístico do corpus textual compreendido pelos inquéritos, ainda que se tenham observado as condições elencadas pelo autor: na seleção de um problema social com aspecto semiótico; na identificação das possibilidades para resolver o problema; na avaliação de como a rede de práticas considera ou não o problema; e na reflexão critica sobre a análise realizada.

Assim, observaram-se o vocabulário técnico ou vulgar, as expressões pejorativas, o duplo sentido, as evasivas; o uso de algumas formas gramaticais como marcadores de reforço, as frases truncadas, repetidas ou incompletas e procedeu-se à busca sistemática de elementos textuais que indicassem as identidades e papéis de gênero socialmente pré-estabelecidos. Procurou-se identificar a presença de artifícios ideológicos - ideologia compreendida como os mecanismos linguísticos para manutenção do status quo - que incluíam a atribuição de culpa às vítimas, os estereótipos de gênero, a presença de preconceitos e discriminação, a patologização de comportamentos sociais. Enfatiza-se que, como pesquisadores do campo da saúde, a ACD não foi usada na perspectiva linguística, mas com o viés de pesquisadores do campo da saúde.

Optou-se pela ACD porque esta perspectiva teórico-metodológica se preocupa com os processos ideológicos que objetivam manter a subordinação de grupos desprivilegiados socialmente e está comprometida politicamente com a denúncia de discursos que (re)produzem as desigualdades, as iniquidades e as discriminações, entendendo que o discurso é um dos mecanismos de legitimação social das relações de poder e de dominação 18,19,20. Para Fairclough 16, a prática social é percebida mediante uma visão da linguagem investida de ideologia e poder, capaz de constituir as dimensões sociais do conhecimento, das relações e da identidade social. Dessa maneira, a perspectiva da ACD auxiliou a compreender como um inquérito policial é construído e permitiu analisar o que dizem os discursos formulados no processo de investigação policial dos assassinatos de mulheres.

Utilizou-se o conceito de polifonia que apresenta uma visão dialógica e múltipla da linguagem segundo a qual mesmo os textos escritos são sempre parte de uma cadeia dialógica, respondendo a formulações anteriores e antecipando outras posteriores. Essa noção de várias vozes que se articulam na interação é fundamental para a compreensão da linguagem como espaço de lutas e contradições, de discursos alinhados ao ponto de vista das minorias desempoderadas, ao mesmo tempo em que propagam ideologias dos grupos no poder 21.

Os discursos analisados neste estudo se referem ao relatório final de 64 inquéritos policiais de mulheres assassinadas na cidade de Porto Alegre, categorizados como feminicídios, oriundos de um total de 89 inquéritos concluídos até 2013. Os 25 inquéritos concluídos que não fizeram parte deste estudo não foram categorizados como feminicídios. A busca de informações iniciou no ano de 2010, quando o Delegado responsável pela Delegacia de Homicídios autorizou a realização da pesquisa, embora ele considerasse que não havia feminicídios entre as mortes femininas por agressão na cidade.

Os inquéritos foram sendo paulatinamente disponibilizados ao grupo de pesquisa, lidos na sua totalidade, compilando-se na íntegra o relatório final. O relatório final é a síntese do inquérito na perspectiva do policial responsável pela sua elaboração, sendo aprovado pelo Delegado, podendo então ser arquivado por ausência de elementos ou ser encaminhado ao judiciário para julgamento do(s) autor(es). O fluxo de um inquérito policial inicia com a realização de um Boletim de Ocorrência, 
seguido de investigação, registrando-se as informações pertinentes ao processo, que incluem depoimentos de testemunhas, laudos de perícia, declaração de óbito e relatório final. Em termos jurídicos o inquérito deve terminar no prazo de 10 dias se o indiciado tiver sido preso em flagrante ou estiver preso preventivamente ou no prazo de 30 dias, quando estiver solto mediante fiança ou sem ela 22 .

O parâmetro de busca era o número de mortes femininas por agressão constantes no sistema de registro de mortalidade do Departamento de Informática do SUS (DATASUS) do Ministério da Saúde. No período 2006-2010, o DATASUS informou a ocorrência de 207 mortes femininas por agressão na cidade de Porto Alegre, entretanto, até o final da pesquisa, foram disponibilizados somente 89 inquéritos, correspondendo a menos da metade do total previsto. Quando se indagava sobre a existência de outros inquéritos, as respostas eram evasivas, ou atribuídas à possibilidade de que as mortes tivessem ocorrido em outras localidades onde teriam sido abertos os inquéritos. Os escrivães diziam não saber o número total de homicídios de mulheres investigados, já que eles não eram arquivados segundo sexo e não havia preocupação em identificar os crimes de gênero.

Os relatórios foram lidos exaustivamente e, para a categorização dos feminicídios, realizou-se a discussão dos dados contidos nos inquéritos, caso a caso. Os critérios para a classificação dos feminicídios incluíram os assassinatos perpetrados por parceiro íntimo atual ou passado confessados pelo autor ou quando havia provas; assassinatos de prostitutas; mortes com violência sexual; mortes em que houve mutilação genital, desfiguração do rosto da vítima ou uso desproporcional dos meios letais; e execuções relacionadas ao tráfico nas quais se considerou que o fato de ser mulher potencializou o crime. Os assassinatos que não foram entendidos como feminicídios incluíram mortes acidentais em tiroteios, brigas, latrocínio ou mesmo execuções em que o fato de ser mulher não gerou o crime, ou seja, situações em que a questão de gênero não era comprovadamente o fator desencadeador da violência.

Os discursos formulados no relatório final dos inquéritos policiais foram analisados nos aspectos relacionados a gênero, tanto na dimensão do crime perpetrado, quanto no aspecto comportamental e social, em que o gênero funciona como um script social para os papéis determinados para cada sexo. Atentou-se para os depoimentos subjetivos ou pessoais que expressavam a opinião ou o ponto de vista do relator e não correspondiam ao regramento penal. Identificaram-se as palavras ou expressões que desqualificavam o comportamento das vítimas e reforçavam as desigualdades de gênero, assim como justificativas para a limitação da ação policial e encerramento precoce dos inquéritos. Os excertos textuais retirados dos inquéritos policiais foram entremeados no texto, utilizando-se itálico para identificá-los.

Este estudo foi aprovado pelo Comitê de Ética e Pesquisa da Escola de Saúde Pública, número 473/09.

\section{Os feminicídios em Porto Alegre}

\section{O que dizem os inquéritos policiais?}

A escolha pelos feminicídios como tema de pesquisa possui um caráter político, pautado na determinação de gênero dessas mortes. Não são mortes acidentais, mas assassinatos de mulheres pelo fato de serem mulheres, que ocorrem pela presença do machismo na sociedade e pela incapacidade do Estado de prevenir tais mortes.

A polícia brasileira tem sido acusada de ser displicente e morosa no processamento das investigações criminais, não recolhendo provas, dispensando testemunhas, desrespeitando os prazos e tempos 7 . Esse fato apareceu na pesquisa, à medida que foi disponibilizada para consulta apenas metade dos inquéritos esperados, segundo os dados registrados no Sistema de Informação sobre Mortalidade (SIM) 23, os operadores não sabiam quantos inquéritos havia, qual a proporção segundo sexo e quantos eram feminicídios.

O inquérito policial foi escolhido como fonte de informação pela possibilidade de aprofundar a compreensão sobre os feminicídios, ausente em outros documentos oficiais. Nos inquéritos policiais, os discursos constituem um coro de vozes de diferentes atores, organizado pelo delegado que tem a responsabilidade de elaborar a síntese final, mesmo quando o documento foi redigido por várias 
mãos, expressando diferentes pontos de vista. Muitas vezes o relatório final do delegado, encerrando o inquérito e enviando ao Ministério Público, é bastante sucinto, mas na maioria das vezes ele explicita a versão da autoridade policial sobre o acontecido. No processo de análise dos inquéritos policiais, observaram-se as marcas subjetivas do redator, o que confere uma diversidade aos inquéritos policiais e expressa a posição política do agente policial frente a esses crimes. Pode haver relativização da gravidade do ato, mas também em alguns relatórios havia empatia para com a vítima. Dessa forma, o inquérito policial constrói, com dados e depoimentos, a identidade dos atores ou as posições em que autores e vítimas são colocados.

A análise incluiu o que estava escrito nos inquéritos policiais, mas também o que não estava escrito, as lacunas e as omissões. A inexistência de mais da metade dos inquéritos policiais, a falta de preenchimento dos dados de identificação de vítimas e autores, dos cenários dos crimes e o não prosseguimento de investigações são elementos que indicam a pouca importância dada a essas mortes. $O$ inquérito policial constitui a primeira etapa para a instauração do processo judicial e se ele não tem elementos suficientes, o caso é encerrado e o crime permanece impune. O entendimento de que os crimes de gênero pertencem à esfera das relações interpessoais em territórios onde há pouca presença do Estado e vigora a impunidade, permitem que a violência masculina homicida dirigida às mulheres aumente, podendo-se afirmar que ela é uma maneira de não interferir no sistema patriarcal e no uso da violência como forma de controle sobre as mulheres 24 .

Os feminicídios considerados inexistentes em Porto Alegre constituíram 64 dos 89 inquéritos analisados. Eram assassinatos de mulheres jovens, com baixa escolaridade, negras, com condição econômica desfavorável, profissões desvalorizadas e um percentual elevado de prostitutas. Os cenários de tráfico presentes em $15 \%$ dos casos, não foram sequer cogitados como possíveis feminicídios. E assim como os crimes de gênero produzem pouca empatia social, o mesmo ocorre em relação às vítimas do tráfico, mulheres pobres e segregadas no espaço urbano, tidas como infratoras, cúmplices dos traficantes e, portanto, merecedoras da morte.

Segundo Adorno 25, há duas possibilidades de leitura de um processo jurídico-policial, a primeira delas permite analisar o crime como aparece nos artigos do Código Penal, avaliando os procedimentos técnicos definidos para cada etapa do processo, compreendendo o inquérito, o julgamento e a sentença. Considera que se devem avaliar os tempos e prazos definidos para cada uma dessas etapas e como os operadores policiais e jurídicos utilizam os materiais e provas, excluindo algumas e dando peso a outras, para organizar a argumentação e o processo. Essa leitura pode ser definida como macrossociológica e aborda o sistema jurídico-policial como instituição. Uma segunda leitura, microssociológica, procura analisar e desvendar o que está por trás das normas. A discussão não se refere mais ao crime, mas à adequação das pessoas envolvidas, ao modelo vigente na sociedade, pautando-se nos padrões aceitáveis ou transgressores do comportamento de homens e mulheres em que o esperado e aceito é a norma de gênero, em que os homens e as mulheres se comportam segundo as normas vigentes.

O objetivo dos julgamentos, segundo Marisa Correa ${ }^{26}$, não é a elucidação dos determinantes sociais e contextuais que levaram ao crime, mas a defesa de um sistema de normas visto como universal. Da mesma forma, o liberalismo difunde o mito da igualdade de justiça para todos, por mais que se saiba que nem todos são iguais frente à justiça e o tratamento é desigual para os que estão em desvantagem na hierarquia social: mulheres, pobres e negros. No Brasil, o modelo liberal de justiça nunca chegou a ser implantado, persistindo as relações fortemente hierarquizadas, calcadas em preconceitos, na intolerância com o outro e no uso de prerrogativas econômicas para a garantia de direitos. Esse fato fica patente nos feminicídios em que predomina o julgamento moral dos atores e a proteção da família e do casamento, supervalorizando a adequação das práticas sexuais femininas 7 . O sistema jurídico-policial, ao julgar casos de violência contra a mulher valoriza, sobretudo, a adequação do comportamento dos envolvidos aos modelos socialmente esperados, em detrimento do enquadramento no código penal 26,27. Assim, o discurso policial e jurídico expressa uma dupla moral no que diz respeito às exigências comportamentais feitas às mulheres em que pesos distintos são atribuídos às atitudes praticadas de acordo com o sexo 28.

Os inquéritos são elaborados mediante vários olhares e falas que tentam compor justificativas para a ocorrência do evento e para o indiciamento ou não de um suposto autor. Os atores envolvidos são testemunhas do assassinato, familiares, amigos e conhecidos das vítimas ou dos autores, podendo incluir policiais e o indiciado. Esses falantes não são neutros em seus posicionamentos; por vezes se 
utilizam de recursos linguísticos para validar estereótipos e incriminar as vítimas, manifestando direta ou subliminarmente posições pessoais e julgamentos morais. Os comportamentos considerados desviantes da vítima ou do autor, se ela é mãe de família, prostituta ou moradora de rua e se ele é rico, provedor ou desempregado irão influenciar a direção imprimida no processo policial.

$\mathrm{Na}$ análise microssociológica dos discursos dos inquéritos policiais, encontrou-se a presença de elementos discursivos ideológicos que reforçam o sistema de subordinação das mulheres 14,24,29,30,31. Esses elementos atribuem valorações distintas às identidades das vítimas, que passam a ser identificadas e avaliadas de acordo com os papeis sociais que desempenham. Assim, elas foram consideradas inadequadas à função esperada de boas esposas e mães por uso de drogas, problemas mentais ou relações extraconjugais; criminosas ou cúmplices quando ligadas ao tráfico; negligentes com sua própria segurança para as que estavam em espaços e horários avaliados como impróprios e, inclusive, para as que não conseguiram romper com a relação de violência, desembocando na atribuição da corresponsabilidade da vítima com a própria morte. Quanto aos agressores, ainda funciona como atenuante a ausência de antecedentes criminais ou o fato de serem trabalhadores. Os agressores pertencentes a classes abastadas são uma minoria, e não foram indiciados.

Durante o processo, dependendo do desfecho desejado, vítimas e agressores podem ter suas vidas vasculhadas e expostas, suas imagens poluídas e a conduta moral atacada, de modo que alguns fatos possam ganhar maior ou menor importância na narrativa 25. Um dos resultados da desqualificação da vítima é romper com a possibilidade de empatia para com elas, induzindo a pensar que as mortes são merecidas e cerceando a indignação social para com os crimes.

\section{A invisibilidade do mal}

As identidades dos atores envolvidos nos feminicídios são construídas nos inquéritos policiais por meio de um amplo cabedal de repertórios e argumentos que incluem a valorização de alguns testemunhos em detrimento de outros, a preferência por uma ou outra prova ou mesmo a constatação de que não há provas, que vigora a lei do silêncio e que o inquérito será encerrado. Logo, cada inquérito pode ser considerado um conjunto de verdades e a consolidação de modelos de vítimas e agressores ou de homens e mulheres na sociedade 7 .

Verificou-se na análise dos discursos formulados nos inquéritos policiais similaridades com o trabalho de Marisa Correa 26 ao mostrar que falas dos agressores são repletas de contradições e lacunas de fatos não explicados, que a maioria nega a autoria do crime ou utiliza a alegação de legítima defesa. Há também os que assumem a responsabilidade pelo assassinato, mas incriminam a conduta da mulher, porque foram traídos, sofriam por amor, fatos que os levaram a experimentar um estado de violenta emoção, argumento ainda usado em substituição à legítima defesa da honra, superado na legislação penal.

A patologização do agressor é um recurso que funciona como uma tentativa para atribuir o evento a situações de anormalidade, eximir ou minimizar a responsabilidade do autor e retirar a conotação social dos crimes de gênero. A atribuição do crime à doença mental, alcoolismo e adição a drogas foi encontrada com elevada frequência nos inquéritos policiais, havendo referências à sociopatia, psicopatia, distúrbios mentais ou depressão, em que a doença, independentemente de existir ou não, tornase uma metáfora ou um adjetivo como na análise de Sontag 32 e significa também a imputabilidade do autor. No relatório final de vários inquéritos de feminicídios íntimos, o agente policial, mesmo indicando a relação de poder que motivou o ato, manteve o discurso da doença: “...é um verdadeiro psicopata, tendo demonstrado sentimento de posse em relação à vítima que há algum tempo buscava a separação”.

Mulheres que querem terminar uma relação marcada pela violência ou se separar sem a concordância dos maridos/companheiros estão em risco de morrer, particularmente quando há ameaças 33,34, fato registrado nos inquéritos policiais da maioria das situações de feminicídio íntimo. Em vários feminicídios íntimos, o companheiro ou ex-companheiro assediava a vítima até encontrá-la e matá-la, processo que iniciava com a negação ou obstrução de um pedido de separação, seguido de brigas, violência física e/ou psicológica, ameaças de morte, finalizando com o feminicídio ${ }^{4}$. Para isso, eles invadiram as casas e as assassinaram diante de familiares e crianças; armaram emboscadas, marcaram encontros letais, fizeram programas que terminaram com a morte. Houve mortes encomendadas a matadores de aluguel como a que vitimou a esposa de um político que ficou impune, descrita em outro 
trabalho ${ }^{10}$. Uma família fugiu para uma cidade do interior na tentativa de proteger a filha ameaçada de morte, todavia o ex-namorado os encontrou mesmo assim, armou uma barreira na rua e executou a jovem. Duas situações foram feminicídios seguidos de suicídio, uma delas de um padrasto que abusava sexualmente da enteada e a mantinha em cárcere privado, declarando em carta que não podia viver sem ela. Um homicida registrou o suicídio da mulher, tentando encobrir um assassinato desvendado no inquérito policial.

A culpa da vítima é um recurso que tem historicamente justificado os crimes de gênero, atribuindo à responsabilidade do ato à inadequação social de uma mulher, que por realizar uma transgressão social, provocou sua própria morte 26 . Foram encontradas desqualificações insidiosas ou abertas às vítimas, críticas a características pessoais, como "preguiça e desmazelo"; alusões a "problemas mentais, ciúmes patológicos, depressão, uso de medicamentos, alcoolismo e drogadição"; uma testemunha afirmou que "a vítima procurou a morte, porque colocou fotografias sensuais com outro rapaz no Orkut". Observou-se o julgamento moral da vítima por não cumprir o papel feminino esperado socialmente: "abandono do filho portador de HIV", "adultério" ou "garota de programa"; ou ainda o uso de roupas inadequadas: "minissaia", "botas de cano alto", "calcinhas vermelhas".

A maior parte dos assassinatos ocorreu nos domicílios, configurando feminicídios íntimos, cujos autores mantinham relações afetivas, sexuais ou familiares com as vítimas. Mais da metade possuía história de violência prévia ao assassinato e uma parcela considerável dessas mulheres havia denunciado à polícia. Familiares, amigos, conhecidos ao depor, declararam conhecer a situação de violência perpetrada contra as vítimas, minimizando o risco e mantendo a noção de que a violência contra a mulher pertence ao âmbito privado.

Uma vez que a violência é um mecanismo social disciplinar de correção das mulheres usado pelo patriarcado para mantê-las subordinadas, esse comportamento é difícil de ser mudado. Além do mais, no modelo biopolítico 35 , a proteção que o Estado oferece é moldada por classe e raça, de modo que as menos valorizadas socialmente estão em maior risco de morrer. A situação em que muitos corpos foram encontrados indica que, em Porto Alegre, há mulheres que morrem porque suas vidas são descartáveis, que possuem pouco ou nenhum valor. Várias foram violentadas física e sexualmente antes do assassinato, outras tiveram os corpos desnudados e mutilados. Foram despejadas em matos, terrenos baldios, estradas. Segundo os inquéritos policiais, havia "corpos desfigurados", "nus”, "com sinais de tortura", "empalação", "violência sexual", "enterrados no quintal”, "jogados dentro de um poço", "queimados", "em porta-malas de carro", "embaixo da cama do namorado", "feridos", "repletos de hematomas", "com sinais de esganação", "número elevado de facadas", "38 disparos pelo corpo", "múltiplos tiros no rosto destruindo a face”.

O não indiciamento do(s) autor(es), deixando esses crimes impunes, reforça a percepção de que essas são mulheres de vidas nuas, precárias, sem valor, que podem, portanto, ser eliminadas 10,36. Os inquéritos policiais em que não houve indiciamento do autor eram predominantemente de mulheres prostitutas ou vinculadas ao tráfico, e os inquéritos foram encerrados rapidamente por "falta de provas". Tais crimes não são percebidos como feminicídios, mas são vistos como decorrentes do comportamento das vítimas, objeto do julgamento moral da sociedade que as responsabiliza pelas suas próprias mortes. "Devido à falta de testemunhas presenciais do crime e à falta de interesse da família da vítima de colaborar com as investigações, não houve indiciamento" é a frase de encerramento de muitos inquéritos policiais, isentando o Estado de dar continuidade à investigação.

Em várias investigações ocorridas em região de precariedade socioeconômica, os moradores, com medo de represálias, não querem identificar-se. Essas investigações são encerradas sem provas e consideradas execuções relacionadas ao tráfico, invisibilizando possíveis crimes de gênero: “...ninguém quer dizer quem foram os autores, após os dois matadores terem atirado na vítima, eles gritaram 'ninguém viu nada', referindo-se à lei do silêncio que impera na localidade e contribui para a impunidade dos crimes". Para Lopes 37 , a impunidade presente no sistema de justiça brasileiro pode ser vista como um privilégio dos mais ricos, dos mais espertos e violentos e dos que têm a sorte de não ser pegos pela polícia. Essa impunidade gerada pelo desaparelhamento do judiciário, corrupção e conivência entre violências e interesses políticos gera inquéritos policiais inconclusivos.

Observou-se a presença marcante dos cenários do tráfico, esse novo tipo de crime em que mulheres são mortas em lugar do companheiro, porque romperam com a lei do silêncio e denunciaram, ou pela demonstração de poder de grupos armados para os quais a execução de uma mulher na frente de outros homens - iguais ou rivais - é uma demonstração de autoridade 13,30. 
Em Porto Alegre, dez execuções de mulheres foram consideradas ligadas ao tráfico, nenhuma delas percebida como feminicídio. Uma dessas mortes correspondeu ao estupro e eliminação de uma líder comunitária que se opunha às atividades de comércio da droga em uma das regiões mais pobres e violentas da cidade. Outras foram mortas por prestar informações à polícia; por "queima de arquivo" ou por ocupar lugar considerado masculino na rígida e generificada hierarquia do tráfico, que usa um poder de milícia, mafioso e patriarcal, paralelo ao poder do Estado. O controle do território se expande no controle do corpo das mulheres, representando a expressão máxima do domínio físico e moral do outro 30 .

Houve mulheres mortas por engano, outras executadas cruelmente; um dos feminicídios aconteceu por disputas ligadas a gênero, porque o posto de chefia no tráfico só pode ser ocupado por homens 30 . A testemunha afirmou: "atiraram na cara dela, porque ela estava administrando a boca no lugar de nego". Desse modo, fecha-se o ciclo: não há testemunhas, os familiares silenciam e a polícia não investiga.

Para os estudiosos do feminicídio 13,30,38, um número cada maior de mulheres está sendo morto em cenários públicos, situações em que a determinação de gênero não aparece. Mas quando se considera a hierarquia de gênero presente no tráfico, percebe-se que a mesma dinâmica que se processa nas relações íntimas está presente no feminicídio público, quando a morte é a punição para uma transgressão de gênero efetuada pela mulher e/ou uma demonstração de poder. Portanto, os feminicídios precisam ser compreendidos em um contexto mais amplo das relações de domínio e controle naturalizadas na cultura patriarcal, com seus múltiplos mecanismos de atemorizar e permitir a impunidade.

Os inquéritos policiais refletem a subjetividade do policial que escreveu o texto, aparecendo julgamentos morais e estereótipos de gênero, mas também expressões de indignação, impotência e raiva frente às dificuldades para realizar os inquéritos, bem como o entendimento das violências como infrações aos direitos humanos das mulheres. Alguns dos textos denunciaram as limitações da ação policial e a impunidade: "mais um homem que mata sua companheira e fica impune, entrando para as estatísticas”. Nessas declarações, os operadores policiais deixaram clara a percepção da desigualdade de poder entre vítimas e agressores: "o motivo torpe evidencia-se a partir do momento em que o agressor matou a vítima pensando ele ser ela sua propriedade”.

Assim sendo, o inquérito policial sumariza a organização de fatos, testemunhos e provas realizada pelos agentes ao selecionar as vozes que serão ouvidas e as que serão silenciadas em um documento cujo desfecho configura a versão final sobre o caso. Esse processo de construção da verdade jurídica da violência contra a mulher foi denominado por Marisa Correa 26 de fábula, entendida como a história construída durante o processo que, ao final, pouco ou nada tem a ver com o que realmente aconteceu.

\section{Considerações finais}

Este estudo analisou os discursos presentes nos inquéritos policiais, na perspectiva da teoria do patriarcado e da análise crítica do discurso. Foi possível verificar que, apesar de haver avanços na legislação e nas políticas públicas, os feminicídios continuam invisibilizados, já que não foram abertos inquéritos para o total das mortes femininas por agressão ocorridas na cidade e, entre os realizados, muitos foram encerrados por falta de provas e indiciamento. $\mathrm{O}$ fato de ter sido disponibilizado pela autoridade policial apenas a metade dos inquéritos policiais, em um período de três anos após a ocorrência das últimas mortes, constitui uma limitação deste estudo, já que essas mortes poderiam não se tratar de feminicídios, mas de outros tipos de agressão. Porém, esse dado também é um indicador do funcionamento precário das instituições de segurança pública porque todas as mortes por homicídio devem ser investigadas, e os inquéritos policiais não disponibilizados podem se referir a investigações encerradas prematuramente, não realizadas, ou ainda casos em que a autoridade policial não deseja expor.

A análise dos inquéritos mostra contradições e disparidades, palavras que culpam e desqualificam as mulheres e banalizam o crime, embora também haja asserções mostrando a condição de desigualdade de poder entre autores e vítimas e o machismo presente na sociedade.

Os feminicídios representam um problema social e político emergente, representando a forma mais extrema de violação dos direitos das mulheres. A análise dos discursos formulados nos inquéri- 
tos policiais permitiu identificar o quanto essas mortes penalizam as jovens, pobres, negras, trabalhadoras sexuais e moradoras da periferia da cidade de Porto Alegre.

A tipificação legal e o reconhecimento da determinação de gênero são ações fundamentais para o enfrentamento dos feminicídios. Muitos poderiam ser prevenidos, por intermédio da identificação das situações de risco e da adoção de medidas protetivas efetivas. Para tanto, são necessárias políticas públicas inclusivas e educação igualitária de gênero que impacte as hierarquias de poder que vulnerabilizam as mulheres em todas as instâncias da sociedade.

\section{Colaboradores}

S. N. Meneghel coordenou o projeto de pesquisa, idealizou o artigo e participou em todas as fases de sua elaboração. A. F. Margarites participou no projeto de pesquisa, coletou os dados e trabalhou na redação do artigo.

\section{Referências}

1. Caputi J, Russel D. Femicidio: la política de matar mujeres. New York: Twayne; 1992.

2. Glass N, Laughon K, Rutto C, Campbell J. Young adult intimate partner femicide. Homicide Stud 2008; 12:177-87.

3. World Health Organization. Understanding and addressing violence against women. Femicide. Geneva: World Health Organization; 2012.

4. Sagot M. Ruta critica de lasmujeresafectadas por la violência intrafamiliar en América Latina: estudios de caso de diez paises. San José: Organización Panamericana de la Salud; 2000.

5. Delphy C. Patriarcado (teorias do). In: Hirata H, Laborie F, Le Doaré H, Senotier D, organizadoras. Dicionário crítico do feminismo. São Paulo: Editora Unesp; 2009. p. 173-8.

6. Saffiotti H. Rearticulando gênero e classe social. In: Costa AO, Bruschini C, organizadores. Uma questão de gênero. Rio de Janeiro: Rosa dos Tempos; 1992. p. 183-215. 
7. Izumino WP. Justiça e violência contra a mulher. O papel do sistema judiciário na solução dos conflitos de gênero. São Paulo: Annablume/FAPESP; 1998.

8. Lagarde M. Antropología, feminismo y política: violência feminicida y derechos humanos de las mujeres. In: Bullen C, Mintegui CD, coordinadoras. Retos teóricos y nuevas practicas. San Sebastián: Ankulegi Antropologia Elkartea; 2008. p. 209-40.

9. Meneghel SN, Hirakata VN. Femicídios: assassinatos de mulheres no Brasil. Rev Saúde Pública 2011; 45:564-74.

10. Meneghel SN, Ceccon RF, Hesler LZ, Margarites AF, Rosa S, Vasconcelos VD. Femicídios: narrativas de crimes de gênero. Interface $\mathrm{Co}$ mun Saúde Educ 2013; 17:523-33.

11. Meneghel SN, Bairros F, Mueller B, Monteiro D, Oliveira LP, Collaziol M. Rotas críticas de mulheres em situação de violência: depoimentos de mulheres e operadores em Porto Alegre, Rio Grande do Sul, Brasil. Cad Saúde Pública 2011; 27:743-52.

12. Brasil. Lei no 13.104 , de 9 de março de 2015 . Altera o art. 121 do Decreto-Lei no 2.848, de 7 de dezembro de 1940 - Código Penal, para prever o feminicídio como circunstância qualificadora do crime de homicídio, e o art. 1o da Lei no 8.072, de 25 de julho de 1990, para incluir o feminicídio no rol dos crimes hediondos. Diário Oficial da União 2015; 10 mar.

13. Carcedo A, organizador. No olvidamos ni aceptamos: femicídio em Centroamérica, 2000-2006. San José: Associación Centroamericana de Información y Acción; 2010.

14. Segato R. Las estructuras elementales de la violencia. Ensayos sobre género entre la antropología, el psicoanálisis y los derechos humanos. Bernal: Universidad de Quilmes; 2003.

15. Salfati CG. Prostitute homicides: a descriptive study. J Interpers Violence 2008; 23:505-43.

16. Fairclough N. Discurso e mudança social. 2a Ed. Brasília: Editora UnB; 2016.

17. Meneghel SN. Femicídios e assassinatos pautados em gênero no Rio Grande do Sul. Projeto de pesquisa. Porto Alegre: Universidade Federal do Rio Grande do Sul; 2010.

18. Magalhães CM. A análise crítica do discurso enquanto teoria e método de estudo. In: Magalhães CM, organizador. Reflexões sobre a análise crítica do discurso. Belo Horizonte: Faculdade de Letras, Universidade Federal de Minas Gerais; 2001. p. 15-30.

19. Magalhães I, Caetano CJM, Bessa D, organizadores. Pesquisas em Análise de Discurso Crítica. São Paulo: Labcom; 2014.

20. Ramalho V. Ensino de língua materna e Análise Crítica de Discurso. Bakhtiniana. Revista de Estudos do Discurso 2012; 7:178-98.

21. Bakhtin MM. Marxismo e filosofia da linguagem. São Paulo: Editora Hucitec; 2014.
22. Brasil. Código Penal Brasileiro. São Paulo: Revista dos Tribunais; 2008.

23. Figueiredo IS, Neme C, Lima CSL, organizadores. Homicídios no Brasil: registro e fluxo de informações. Brasília: Secretaria Nacional de Segurança Pública, Ministério da Justiça; 2013.

24. Biglia B, San Martin C. Estado de wonderbra. Entretejiendo narraciones feministas sobre las violencias de género. Barcelona: Virus Editorial; 2007.

25. Adorno S. Os aprendizes do poder. O bacharelismo liberal na política brasileira. São Paulo: Editora Paz e Terra; 1988.

26. Correa M. Morte em família: representações jurídicas de papéis sexuais. Rio de Janeiro: Edições Graal; 1983.

27. Andallion D, Debert G. Quando a vítima é mulher. Análise de crimes de estupro, espancamento e homicídio. Brasília: Conselho Nacional dos Direitos da Mulher; 1987.

28. Pandjiarjian V. Estereótipos de gênero nos processos judiciais e a violência contra a mulher na legislação. In: Moraes MLQ, Naves R, organizadores. Advocacia pro bono em defesa da mulher vítima de violência. São Paulo: Imprensa Oficial do Estado de São Paulo/Editora da Unicamp; 2002. p. 75-106.

29. Carcedo A, Sagot M. Femicidio en Costa Rica 1990-1999. Washington DC: Organización Panamericana de la Salud; 2000. (Colección Teórica, 1).

30. Segato R. Qué es um femicidio? Notas para um debate emergente. Brasília: Editora UnB; 2006.

31. Pasinato W. "Femicídios" e as mortes de mulheres no Brasil. Cadernos Pagu 2011; (37):219-46.

32. Sontag S. A doença como metáfora. Rio de Janeiro: Edições Graal; 1984.

33. Campbell JC, Webster D, Koziof-Mclain J, Block C, Campbell D, Curry MA, et al. Risk factors for femicide in abusive relationships: results of a multicase case control study. Am J Public Health 2003; 93:1089-97.

34. Campbell JC, Sharps PW, Laughon K, Bloom $\mathrm{T}$. Intimate partner homicide: review and implications of research and policy. Trauma Violence Abuse 2007; 8:246-69.

35. Foucault M. Microfísica do poder. Rio de Janeiro: Edições Graal; 1979.

36. Agambem G. Homo sacer: o poder soberano e a vida nua. Belo Horizonte: Editora UFMG; 2007.

37. Lopes JR. Justiça e poder judiciário ou a virtude confronta a instituição. Rev USP 1994; 21:22-33.

38. Fragoso JM. Feminicidio sexual serial em Ciudad Juarez: 1993-2001. Debate Feminista 2002; 25:1-16. 


\section{Abstract}

Femicide is the murder of women as the result of gender inequalities. It is the most extreme form of violence against women. The theoretical and methodological frame of reference used in this study was patriarchy theory and critical discourse analysis. We analyzed the discourses from 64 police inquiries categorized as femicides in Porto Alegre, Rio Grande do Sul State, Brazil, from 2006 to 2010. The victims were mostly poor young women living in outlying areas of the city with high rates of prostitution and women murdered by the drug traffic, deaths not routinely classified as femicides by the police. Many inquiries were shelved for purported lack of evidence, and many other cases were not even started. The discourse in the police reports often demeaned and blamed the victims, although some criticized the inequalities between men and women and identified the lethal effects of male chauvinism. Police inquiries are important sources for studying femicide in society, adding abundant information on the crimes' victims, perpetrators, and scenarios.

Homicide; Violence Against Women; Sexism

\section{Resumen}

Los feminicidios son asesinatos de mujeres, resultado de desigualdades de género, que representan la forma más extrema de violencia contra la mujer. El marco de referencia teórico-metodológico utilizado en este estudio fue la teoría del patriarcado y el análisis crítico del discurso. Se analizaron los discursos referentes al informe final de 64 investigaciones policiales, categorizadas como feminicidios, ocurridas en la ciudad de Porto Alegre, Rio Grande do Sul, Brasil, durante el período de 2006 a 2010. Las victimas eran mayoritariamente mujeres pobres, jóvenes y habitantes de regiones de periferia, existiendo una frecuencia elevada de prostitutas y mujeres ejecutadas por el tráfico de drogas; muertes no consideradas feminicidios por los operadores policiales. Muchas investigaciones se archivaron, debido a la ausencia de pruebas, y otras ni siquiera fueron iniciadas. En estas investigaciones, habia discursos que descalificaban y culpaban a las victimas, pese a que algunos criticasen las desigualdades entre hombres y mujeres $e$ identificasen los efectos letales del machismo. Las investigaciones policiales son fuentes importantes para estudiar el feminicidio en la sociedad, añadiendo una gran cantidad de información sobre víctimas, agresores y escenarios de los crimenes.

Homicidio; Violencia contra la Mujer; Sexismo
Recebido em 28/Set/2016

Versão final reapresentada em 13/Mar/2017

Aprovado em 03/Abr/2017 